\title{
Autoimmune encephalitis: differences of clinical features between antibody-positive and antibody- negative conditions
}

Tingting Li

Shandong Qianfoshan Hospital

\section{Zhihua Si}

Shandong Qianfoshan Hospital

Lu Lu

Shandong Qianfoshan Hospital

Aihua Wang ( $\nabla$ aihuawang2018@sina.com )

Research article

Keywords: Autoimmune encephalitis; Antibody-positive; Antibody -negative

Posted Date: April 12th, 2019

DOI: https://doi.org/10.21203/rs.2.9140/v1

License: (c) (i) This work is licensed under a Creative Commons Attribution 4.0 International License. Read Full License 


\section{Abstract}

Autoimmune encephalitis is a kind of immune disease with a higher incidence while classification and analysis based upon different states of antibodies are scarcely reported. We intend to compare the clinical features of autoimmune encephalitis between antibody-positive and antibody-negative, with a goal of contributing to early diagnosis and facilitate clinical treatment decisions, especially concerning antibody negative cases. A total of 38 patients with autoimmune encephalitis were enrolled and patients with infections, hereditary, metabolic or toxic neurological diseases were excluded. Based on the serum and cerebrospinal fluid (CSF) antibody results, all patients were divided into antibody-positive group and antibody-negative group. The clinical manifestations of the two groups were compared in detail. The number of antibody-positive group with immuno-related injury $(\mathrm{p}=0.012)$, number of combined symptoms $(p=0.027)$ and abnormal secretion of exocrine glands $(p=0.023)$ were higher than antibody-negative group; patients with psychiatry department treatment history exceeded antibody-negative group $(p=0.014)$ and patients with epileptic of antibody-positive group was less than that of antibody-negative group ( $p=0.028)$. Majority of patients in antibody-positive group displayed cerebrospinal fluid (CSF) pressure and white blood cell (WBC) count increased while that in a small number of antibody-negative group $(p=0.043, p=0.045)$. Baseline mRS scores of antibody-positive group were higher than negative group at admission $(p=0.049)$, and $m R S$ in both groups were significantly lower at discharge than admission $(p=0.010, p=0.011)$. Compared with antibody-negative group, the combined therapy in antibody-positive group was more common ( $p=0.025)$. Although antibody-positive patients may have more serious conditions,but the data suggest that in spite of some differences between antibody positive and negative patients, they are quite similar and perhaps should be subjected to the same rigorous treatment or management protocols. Immunotherapy might play an important role in relieving symptoms.

\section{Background}

Autoimmune encephalitis (AE), a group of autoantibody-mediated neuronal cell destruction disorders, has a diverse manifestations with acutely or subacute onset, accompanied by neuropsychiatric behavior, memory loss, seizures, sometimes decreased levels of consciousness, abnormal exercise and autonomic dysfunction [1]. In addition, some patients have potential risk for mergers neoplasm [2]. It can be happened in all age and accounts for a high proportion in non-infectious encephalitis [3]. The researchers have identified that $A E$ has a high disability rate, and may have a fatal outcome without early immunotherapy [4].

We found in clinical practice that antibody-negative patients are common and its pathogenesis is unclear [14]. Probably because antibody-negative AE have only been identified in the last few years. As far as we know, there is currently few comparative study of $A E$ with the different states of antibodies. Further understanding the different antibody states of $A E$ on the clinical features with differences and similarities may be beneficial to early clinical decisions. To have a better understanding of $A E$, we will preliminarily compare the clinical features among antibody-positive and antibody-negative patients. 


\section{Methods}

\section{Patient selection}

The term AE or possible AE patients were searched in the digital archive of discharge reports of Qianfoshan hospital between 2016 and 2018. The clinical features are consistent with the latest version of the diagnostic criteria for AE published by Lancet Neurol in 2016[2]. If anti-neuronal surface or synaptic antibody positive, and exclude other possible causes, antibody-positive AE can be directly diagnosed. Antibody-negative $A E$ can be made when the following conditions are met: 1.Fast progression within 3 months of recent memory deficits, altered state of consciousness, or psychiatric symptoms. 2. Exclusion of encephalitis syndrome with defined causes. 3.Absence of characterised autoantibodies in cerebrospinal fluid (CSF) and serum, and at least two of the following criteria: a. Magnetic resonance imaging (MRI) abnormalities implicit of AE; b. CSF pleocytosis, CSF-specific oligoclonal bands or elevated CSF IgG index, or both ; c. Brain tissue biopsy shows inflammatory infiltration, excluding other disorders d. Rational exclusion of other possible causes. Patients with infections, hereditary, metabolic, toxic neurological diseases or antibodies negative in CSF and positive in serum were excluded. Patients who had an incomplete clinical data were also excluded. All patients CSF and serum samples were sent to Jinan Golden Medical Testing Center to detect the antibodies of central nervous system AE(detection types include NMDA-R-Ab, AMPA1-R-Ab, AMPA2-R-Ab, GABAB -R-Ab, LGI1-Ab, CASPR2-Ab, GAD65-Ab) and para-neoplastic syndrome autoantibodies were excluded from paraneoplastic diseases or sent to Tianjin Huada Genetic Testing Institute for high-throughput genetic testing of infectious agents in order to rule out infectious diseases. All patients, according to the serum and CSF antibody results, were divided into antibody-positive group (22 cases) and antibody-negative group (16 cases). And the antibody-positive group was included 4 subgroups according to the type of antibodies including NMDAR (15cases), LGI1 (4cases), GABAB (2cases), AMPA1 (1cases). The patients' medical information were obtained from the inpatient history, as well as the descriptions of his or her attending physicians and family members. All patients received immunotherapy after completing laboratory tests during hospitalization, and the immunotherapy effect was evaluated according to Modified Rankin Scale (mRS) score which were evaluated on admission and discharge respectively. Ethical approval for this study was from the Qianfoshan Hospital Ethical Committee. Informed consent comes from the patients or their guardians.

Statistical analysis: Statistical software using SPSS20.0. The Student's T test and the Fisher's exact test were used for analysis the differences between variables, then, the results of test are reported accordingly. Statistical differences were considered meaningful when $\mathrm{P}<0.05$.

\section{Results}

\section{Comparison of clinical manifestations}

There are no differences of the gender and age in two groups. And no differences were seen for the number of patients in intensive care unit (mainly due to unsatisfactory seizure control or persistent 
hypoventilation disorder, $\mathrm{p}=0.675)$ or the days of hospitalization between the two groups $(P=0.102)$. Patients with immune-related injury history that including hypothyroidism, hyperthyroidism, rheumatoid arthritis and type I diabetes, and psychiatry department history of treatment in antibody-positive group significantly exceeded antibody-negative group $(p=0.012, p=0.014)$. The basic symptom types of the two groups were basically same, but the number of multiple types of symptoms were higher in antibodypositive group $(P=0.027)$. Furthermore, patients with seizure in antibody-negative group significantly exceeded antibody-positive group $(\mathrm{p}=0.028)$ and abnormal secretion of exocrine glands, including hypersecretion of salivary and sweat glands, was significantly less than antibody-positive group $(p=0.023)$. Demographics and clinical data for both groups are shown in Table 1.

CSF analysis, EEG and MRI studies

The pressure and white blood cell (WBC) count of CSF were found to be increased in both groups, which was more common in antibody-positive group. The abnormal value of CSF pressure is from $200 \mathrm{mmH} 20$ to $250 \mathrm{mmH} 2 \mathrm{O}$, and of $\mathrm{WBC}$ count is 10 to $50 / \mathrm{mm} 3$. The CSF-High-throughput seuencing were no abnormalities found in both groups, which could exclude the presence of infection. The incidence rates of Electroencephalography (EEG) abnormal were equivalent $(p=0.36)$ in two groups, mainly expressed as low-amplitude background rhythm. Abnormal hyperintensity signal of T2/Flair was found in head MRI which was consistent with the manifestation of encephalitis. No differences were seen of multiple MRI abnormalities between the two groups, with temporal lobe, insular lobe and hippocampus being the most common. Table2 shows the general analysis.

\section{Comparison of neurological status and immunotherapy}

The two groups were treated with different immunotherapy methods, the positive group would be more likely received combined therapy (corticosteroids and intravenous immunoglobulins(IVIG) ) and the negative group more likely received monotherapy(corticosteroids or IVIG). Both groups have a dramatically decline of mRS after immunotherapy (Table4, 5). Baseline mRS scores of antibody-positive group were not significantly different from that of the antibody-negative group at discharge, but at admission were significantly upper than those in antibody-negative group $(p=0.220, p=0.049$, respectively) (Table3, 4).

\section{Discussion}

$A E$ is divided into two categories of antibody-positive $A E$ and antibody-negative $A E$ by antibody testing that has become an increasingly recognized [15]. However, only a few studies have compared the clinical features or outcomes in AE patients with the different states of antibodies. Our study showed that the symptoms of antibody-positive patients are relatively severer and more complicated than antibodynegative patients, but both can benefit from immunotherapy.

Patients with different states of antibodies have very similar clinical characteristics [16], and also showed similar in auxiliary inspection findings [17]. However, clinicians sometimes pay insufficient attention to 
antibody-negative and consider that it uncorrelated to $A E$, leading to misdiagnosis or delay diagnosis. Clinicians often found both types AE may have a significant improvement in the early stages of after immunotherapy and showed similar short-term prognosis and neurological dysfunction, which also be

confirmed by Yael Hacohen [14]. Because in our study that the patients with positive antibody had severer neurological symptoms at admission and more likely received combined therapy, which is superior to monotherapy previous literature reports [18]. Therefore, it does not indicate which types of patients are more sensitive to immunotherapy, but can be explained that the immune response is closely related to both types of $\mathrm{AE}$. Our study also confirmed that $\mathrm{AE}$ is an immune-mediated disease.

Interestingly, exacting comparison of clinical features still reveal differences. Our study showed that antibody-positive $A E$ are more likely to have medical history of immune-related injuries, and studies on other types of immune diseases have also been found a similar phenomenon that the presence of antibody in the body often accompanied with other immunity disease [19-20]. Since antibody-positive patients more likely to have medical history of immune-related injury, multiple immune injuries coexist will inevitably lead to the poorer of their immunologic function, therefore the distinction between antibody-positive and antibody-negative has important clinical significance. On the other hand, as showed in our study, compared with antibody-negative patients, antibody-positive patients were often accompanied by abnormal secretion of exocrine glands. Immune injury is one of the main causes of abnormal secretion of exocrine glands, which is widely recognized in present study [21]. Considering the potential relationship between antibody status and immune injury, we speculate that the body suffer immune injury might easier to induce the occurrence of other immune diseases, those conditions are existed in antibody-positive AE which was reported by Ohkawa T [22-23], but not in antibody-negative AE, although further investigations are needed. Furthermore, the state of antibodies may reflect the severity of immune damage, as found by others that the antibody level could be reduced as the improvement of symptoms [10]. As expected, it can also be fully validated in our study that patients with antibody-positive patients have more clinical symptoms, more abnormalities in pressure and WBC count of CSF. Further prospective studies are necessary to confirm this hypothesis.

In addition, it is not clear why antibody negative patients are prone to suffer epileptic while the mechanism of immune damage cannot be completely explained reasonably. However, other researchers found that epileptic which is caused by AE can have better responses to immunotherapy than anti-seizure medication [24]. Still some unexplored causes are existed, and the further investigations of patients with antibody negative may lead to discover of new pathogenic mechanisms. And more fundamental experimental researches are necessary in the future.

\section{Conclusions}

Antibody-negative patients are not rare and its clinical features are similar to those of antibody-positive patients. A few differences may be related to the degree of immune damage. Immunotherapy might play an important role in relieving symptoms. The pathogen and mechanism of the disease should be further investigated in the future. 


\section{Abbreviations}

AE囚Autoimmune encephalitis;

mRS: Modified Rankin Scale;

IVIG: Intravenous immunoglobulins;

EEG囚Electroencephalography
CSF『cerebrospinal fluid;

WBC凶White blood cells;

MRI区Magnetic resonance imaging;

\section{Declarations}

\section{Ethics approval and consent to participate}

This study was approved by the Ethics Committee of Affiliated Qianfoshan Hospital of Shandong University. All patients or the patient's next-of-kin provided written informed consent to participate if a patient could not sign due to disability. And this was also approved by the ethics committee. A copy of the written consent is available for review by the Editor of this journal.

\section{Consent for publication}

Written informed consent was obtained from the patients for publication of this research and any accompanying images or from the patient's next-of-kin if a patient could not sign informed consents due to disability.

\section{Availability of data and materials}

The datasets used and/or analysed during the current study are available from the corresponding author on reasonable request.

\section{Conflicts of interest}

There are no conflicts of interest.

\section{Funding:}

Data collection, analysis, and interpretation of the study was supported by grants from the Natural Science Foundation of Shandong Province (No. ZR2016HP23) and the Science and Technology Develop Project of Jinan (No. 201704113).

\section{Authors' contributions}

Tingting Li collected and analyzed data, and drafted the manuscript. Zhihua Si and Lu Lu participated in the acquisition and interpretation of data, and were involved in revising the manuscript. Aihua Wang conceived of the study, and helped to draft and revise the manuscript. All authors read and approved the final manuscript, and agreed to be accountable for all aspects of the work. 
Acknowledgements

The authors thank the patients and their families, clinicians and nursing staff of Qianfoshan Hospital for their cooperation. The authors also thank the anonymous reviewers for their helpful comments.

Authors' information

Ting-Ting Lia ${ }^{a}$ Zhi-Hua Si ${ }^{b}, L^{2} L^{b}$, Ai-hua Wang ${ }^{\text {b* }}$

aDepartment of Neurology, Shandong Provincial Qianfoshan Hospital, Taishan Medical University, Jinan, China

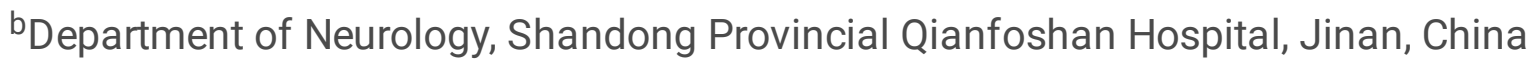

*Corresponding author: Ai-Hua Wang, MD, Department of Neurology, Shandong Provincial Qianfoshan Hospita, 66 Jingshi Road, Jinan 250014, Shandong province, China.

E-mail: aihuawang2018@sina.com

\section{References}

1. Ramanathan S, Mohammad SS, Brilot F, Dale RC, Brilot F, Dale RC. Autoimmune encephalitis: Recent updates and emerging challenges. J Clin Neurosci 2014; 21(5):722-30.

2. Graus F, Titulaer MJ, Balu R, Benseler S, Bien CG, Cellucci T, et al. A clinical approach to diagnosis of autoimmune encephalitis. Lancet Neurol 2016; 15(4): 391-404.

3. Kalman B. Autoimmune Encephalitides: A Broadening Field of Treatable Conditions. Neurologist $2017 ; 22(1): 1-13$.

4. Vora NM, Holman RC, Mehal JM, Steiner CA, Blanton J, Sejvar J. Burden of encephalitis-associated hospitalizations in the United States, 1998-2010. Neurology2014; 82(5):443-451.

5. Dalmau J, Graus F. Antibody-mediated encephalitis. N Engl J Med 2018; 378(9):840-851.

6. Platt MP, Agalliu D, Cutforth T. Hello from the other side: how autoantibodies circumvent the bloodbrain barrier in autoimmune encephalitis. Front Immunol 2017; 8:442.

7. Dalmau J. NMDA receptor encephalitis and other antibody-mediated disorders of the synapse: the 2016 Cotzias lecture. Neurolog 2016; 87(23):2471- 2482.

8. Lancaster E, Martinez-Hernandez E, Dalmau J. Encephalitis and antibodies to synaptic and neuronal cell surface proteins. Neurology2011;77(2):179-189.

9. Zuliani L, Graus F, Giometto B, Bien C, Vincent A. Central nervous system neuronal surface antibody associated syndromes: review and guidelines for recognition. J Neurol Neurosurg Psychiatry 2012; 83(6):638-645.

10. Titulaer MJ, Höftberger R, lizuka T, Leypoldt F, McCracken L, Cellucci T, et al. Treatment and prognostic factors for long-term outcome in patients with anti-NMDA receptor encephalitis: an 
observational cohort study. Lancet Neurol 2014; 12(2):157-165.

11. Ganesh A, Wesley SF. Practice Current: When do you suspect autoimmune encephalitis and what is therole of antibody testing? Neurol Clin Pract 2018; 8(1):67-73.

12. 12.Dale RC, Merheb V, Pillai S, Wang D, Cantrill L, Murphy TK, et al. Antibodies to surface dopamine-2 receptor in autoimmune movement and psychiatric disorders. Brain 2012; 135(Pt 11):3453-68.

13. Lancaster E. The diagnosis and treatment of autoimmune encephalitis. J Clin Neurol 2016; $12: 1-13$. 14. Hacohen Y, Wright S, Waters P, Agrawal S, Carr L, Cross H, et al. Paediatric autoimmune encephalopathies: clinical features, laboratory investigations and outcomes in patients with or without antibodies to known central nervous system autoantigens. J Neurol Neurosurg Psychiatry 2012; 84(7):748-55.

14. Najjar S, Pearlman D, Zagzag D, Devinsky O. Spontaneously resolving seronegative autoimmune limbic encephalitis. Cogn Behav Neurol 2011; 24(2):99-105.

15. Wingfield T, McHugh C, Vas A. Autoimmune encephalitis \a case serise and comprehensive review of the literature. QJM 2011; 104囚11区: 921-31.

16. Lee SK, Lee ST. The laboratory diagnosis of autoimmune encephalitis. J Epilepsy Res 2016; 6:45-52.

17. Varley J, Taylor J, Irani SR Autoantibody-mediated diseases of the CNS: structure, dysfunction and therapy. Neuropharmacology 2017; 132:71-82.

18. Tüzün E, Erdağ E, Durmus H, Brenner T, Türkoglu R, Kürtüncü $M$, et al. Autoantibodies to neuronal surface antigens in thyroid antibody-positive and -negative limbic encephalitis. Neurology India 2011; 59(1):47-50.

19. Nakamura H, Usa T, Motomura M, Ichikawa T, Nakao K, Kawasaki E, et al. Prevalence of interrelated autoantibodies in thyroid diseases and autoimmune disorders. J Endocrinol Invest 2008; 31(10):8615.

20. Stasulis CA, Hand AR. Immunohistochemical identification of antigen presenting cells in rat salivary glands. Arch Oral Biol 2003; 48(10):691-9.

21. Ohkawa T, Satake S, Yokoi N, Miyazaki Y, Ohshita T, Sobue G,et al. Identification and characterization of $\mathrm{GABA}(\mathrm{A})$ receptor autoantibodies in autoimmune encephalitis. J Neurosci 2013; 34(24):8151-63.

22. Haitao,R, Autoimmune encephalitis associated with vitiligo? Journal of Neuroimmunology 2017; 310:14-16.

23. Steiner J, Prüss H, Köhler S, Frodl T, Hasan A, Falkai P. Autoimmune encephalitis with psychosis: Warning signs, step-by-step diagnostics and treatment. World J Biol Psychiatry 2018; 4:1-25.

24. Aravind Ganesh, MD, and Sarah F. Wesley, MD, MPH. Practice Current When do you suspect autoimmune encephalitis and what is therole of antibody testing? Clinical Practice 2018; 8: 1 67-73.

\section{Tables}

Table1. Comparison of clinical features among the antibody positive and antibody negative groups 


\begin{tabular}{|c|c|c|c|}
\hline & $\begin{array}{l}\text { Antibody-positive } \\
\text { group } \square \mathrm{n}=22 \square\end{array}$ & $\begin{array}{l}\text { Antibody-negative } \\
\text { group } \llbracket \mathrm{n}=16 \square\end{array}$ & $\begin{array}{c}\mathrm{P} \\
\text { values }\end{array}$ \\
\hline Male & 12 & 9 & 1.000 \\
\hline \multirow[t]{2}{*}{ Age } & $38.1 \pm 21.8$ & $46.3 \pm 21.5$ & 0.259 \\
\hline & (range $2-78$ ) & (range13-83) & \\
\hline ICU & 5 & 2 & 0.675 \\
\hline Hospitalization days & $25.32 \pm 12.87$ & $20.00 \pm 10.52$ & 0.102 \\
\hline psychiatry department & 7 & 0 & $0.014^{*}$ \\
\hline Neoplasm & 3 & 2 & 1.000 \\
\hline Immune related injury & 10 & 1 & $0.012 *$ \\
\hline Prodromal symptoms & 13 & 5 & 0.112 \\
\hline \multicolumn{4}{|l|}{ Clinical manifestation } \\
\hline 1) Seizures & 10 & 13 & $0.028^{*}$ \\
\hline Generalised & 8 & 10 & \\
\hline Focal & 2 & 3 & \\
\hline 2) Psychiatric and behavioural changes & 16 & 11 & 1.000 \\
\hline 3) Memory disorders & 12 & 4 & 0.100 \\
\hline 4) Speech disorders & 10 & 3 & 0.165 \\
\hline 5) Involuntary movement & 7 & 2 & 0.254 \\
\hline 6) Consciousness disorders & 9 & 2 & 0.078 \\
\hline 7) Central hypoventilation & 5 & 2 & 0.675 \\
\hline 8) Sensory disorders & 2 & 1 & 1.000 \\
\hline 9) Autonomic dysfunction & 17 & 11 & 0.713 \\
\hline 1. abnormal secretion of exocrine glands & 7 & 0 & $0.023^{*}$ \\
\hline 2.sleep disorders & 8 & 3 & 0.435 \\
\hline 3.Orthostatic hypotension & 1 & 0 & 1.000 \\
\hline 4.Urinary or stool abnormalities & 5 & 4 & 1.000 \\
\hline 5.Sinus bradycardia/speed & 6 & 4 & 1.000 \\
\hline Number of symptoms & $4.18 \pm 1.097$ & $3.38 \pm 1.025$ & $0.027 *$ \\
\hline
\end{tabular}

ICU-Intensive care unit $\square *-\mathrm{P}<0.05$

Table2. Comparison of auxiliary examination between antibody positive and antibody negative groups 


\begin{tabular}{|c|c|c|c|}
\hline & Antibody-positive Group $\llbracket n \square$ & Antibody-negative group $\llbracket \mathrm{n} \square$ & $\begin{array}{c}\mathrm{P} \\
\text { values }\end{array}$ \\
\hline & $\mathrm{n}=22$ & $\mathrm{n}=16$ & \\
\hline CSF pressure increases & 12 & 3 & $0.043^{*}$ \\
\hline CSF-WBC increases & 14 & 4 & $0.025^{*}$ \\
\hline \multirow[t]{2}{*}{ CSF-protein increases } & 3 & 5 & 0.243 \\
\hline & $\mathrm{n}=13$ & $\mathrm{n}=15$ & \\
\hline EEG abnormalities & 11 & 11 & 1.000 \\
\hline 口Delta rhythm or delta brush & 2 & 0 & 0.476 \\
\hline 口Low-amplitude background rhythm & 8 & 9 & 1.000 \\
\hline \multirow[t]{2}{*}{ ¿Sharp or slow composite waves } & 1 & 2 & 1.000 \\
\hline & $\mathrm{n}=21$ & $\mathrm{n}=16$ & \\
\hline MRI abnormalities & 7 & 10 & 0.104 \\
\hline MRI Lesions (unilateral/bilateral) & 4 & 4 & 0.637 \\
\hline \multicolumn{4}{|l|}{ Locations } \\
\hline ૧Temporal lobe/insular lobe/hippocampus & 5 & 9 & 0.537 \\
\hline ๑Basal ganglia & 1 & 3 & 0.603 \\
\hline 口Pons & 1 & 1 & 1.000 \\
\hline 口Frontal lobe & 1 & 0 & 0.412 \\
\hline ¿Corpus callosum & 0 & 1 & 1.000 \\
\hline 口Thalamus & 1 & 0 & 0.412 \\
\hline
\end{tabular}

CSF-Cerebrospinal fluid, EEG- Electroencephalography, MRI- Magnetic resonance imaging, WBC- White blood cells, *-P $<0.05$

Table3. Comparison of mRS score at admission and discharge

\begin{tabular}{lllcc}
\hline & \multicolumn{2}{c}{ Antibody-positive group $(\mathrm{n}=22)$} & \multicolumn{2}{c}{ Antibody-negative group $(\mathrm{n}=16)$} \\
\cline { 2 - 5 } mRS score & At admission $\llbracket \mathrm{n} \square$ & At discharge $\llbracket \mathrm{n} \square$ & At admission $\square \mathrm{n} \square$ & At discharge $\square \mathrm{n} \square$ \\
\hline 0 & 0 & 1 & 0 & 2 \\
1 & 0 & 5 & 0 & 4 \\
2 & 2 & 6 & 6 & 6 \\
3 & 10 & 6 & 7 & 3 \\
4 & 2 & 2 & 0 & 0 \\
5 & 8 & 2 & 3 & 1 \\
6 & & 0 & & 0 \\
\hline
\end{tabular}

mRS- Modified Rankin Scale 
Table4. Comparison of immunotherapy method and change of mRS mean

\begin{tabular}{cllc}
\hline & Antibody-positive group(n=22) & Antibody-negative group(n=16) & P \\
& & & values \\
\hline Single /double drug & $8 / 14$ & $12 / 4$ & $0.025^{*}$ \\
corticosteroids & 7 & 9 & 0.188 \\
IVIG & 1 & 3 & 0.291 \\
At admission mRS & $3.72 \pm 1.08$ & $3.00 \pm 1.10$ & $0.049^{*}$ \\
At discharge mRS & $2.41 \pm 1.33$ & $1.88 \pm 1.26$ & 0.220 \\
\hline
\end{tabular}

IVIG- Intravenous immunoglobulins, mRS-modified Rankin Scale, *-P<0.05

Table5. The changes of mRS mean at admission and discharge of themselves were compared

\begin{tabular}{lccc}
\hline & At admission mRS & At discharge mRS & P values \\
\hline antibody-positive & $3.72 \pm 1.08$ & $2.41 \pm 1.33$ & $0.010^{*}$ \\
antibody-negative & $3.00 \pm 1.10$ & $1.88 \pm 1.26$ & $0.011^{*}$ \\
\hline
\end{tabular}

mRS - modified Rankin Scale, $*$-P $<0.05$ 